\title{
Haemoglobin phenotypes and the risk of asymptomatic malaria parasitemia among blood donors in northwest Nigeria: clinical implications in the practice of tropical transfusion medicine
}

\author{
${ }^{1}$ Kani, K. M., ${ }^{2}$ Ibrahim, Z., ${ }^{2}$ Habeeb, A., ${ }^{3}$ Ibrahim, U. A., and ${ }^{* 4}$ Ahmed, S. G. \\ ${ }^{1}$ Department of Haematology, Federal Medical Centre, Birnin Kudu, Nigeria \\ ${ }^{2}$ Department of Haematology, Rasheed Shekoni Teaching Hospital, Dutse, Nigeria \\ ${ }^{3}$ Department of Paediatrics, Aminu Kano Teaching Hospital, Kano, Nigeria \\ ${ }^{4}$ Department of Haematology, Aminu Kano Teaching Hospital, Kano, Nigeria \\ *Correspondence to: drsagirahmed@yahoo.com; +2348034418015
}

\begin{abstract}
:
Background: In malaria-endemic populations, sickle cell trait (SCT) protects against both severe and non-severe malaria, but inconsistencies exist about protective effect of SCT on asymptomatic malarial parasitemia (AMP). Surprisingly, the effect of $\mathrm{Hb}$-phenotypes on AMP has not been explored among blood donors in Nigeria or other malaria-endemic countries, where risks of AMP and transfusion transmitted malaria (TTM) are high. The objective of this study is to determine risk of AMP with respect to donor Hb-phenotypes (SCT versus HbAA), and elucidate clinical implications of AMP with respect to risk of TTM vis-à-vis the practice of transfusion medicine in Nigeria, and by implication other malaria-endemic tropical countries.

Methodology: Analysis of 100 blood donors with AMP (cases) and 100 donors without AMP (controls) was performed. Frequencies of SCT and $\mathrm{HbAA}$ (determined by $\mathrm{Hb}$ electrophoresis) among cases and controls were compared by $X^{2}$-test. Risks of AMP (detected by microscopy) with respect to Hb-phenotypes were expressed as Odds ratios (OR) by case-control logistic regression.

Results: In comparison with blood donor without AMP (controls), donors with AMP had lower frequencies of SCT $(12 \%$ vs $28 \%, p<0.05)$ with corresponding higher frequencies of $\mathrm{HbAA}(88 \%$ vs $72 \%, p<0.05)$. HbAA is associated with high risk of AMP $(\mathrm{OR}=2.91,95 \% \mathrm{CI}: 2.10-3.48, p=0.021)$, while SCT is associated low risk of AMP (OR=0.49, 95\%CI: $0.27-0.73, p=0.032$ ).

Conclusion: This finding shows that donor SCT is a surreptitious mitigator of the risk of AMP and TTM in the tropics. Therefore, patients who are selectively transfused with HbAA blood (e. g. neonates and sickle cell disease patients) could be at greater risks of TTM, and such patients need closer post transfusion monitoring. The risk of TTM calls for diligent post transfusion haemovigilance in Nigeria and other malaria endemic tropical countries in Africa
\end{abstract}

Keywords: blood donors, sickle cell trait, asymptomatic malaria parasitemia, transfusion transmitted malaria

Received Oct 13, 2020; Revised Jan 2, 2021; Accepted Jan 3, 2021

Copyright 2021 AJCEM Open Access. This article is licensed and distributed under the terms of the Creative Commons Attrition 4.0 International License <a rel="license" href="http://creativecommons.org/licenses/by/4.0/", which permits unrestricted use, distribution and reproduction in any medium, provided credit is given to the original author(s) and the source. Editor-in-Chief: Prof. S. S. Taiwo

\section{Phénotypes d'hémoglobine et risque de parasitémie asymptomatique du paludisme chez les donneurs de sang dans le nord-ouest du Nigéria: implications cliniques dans la pratique de la médecine transfusionnelle tropicale}

\author{
${ }^{1}$ Kani, K. M., ${ }^{2}$ Ibrahim, Z., ${ }^{2}$ Habeeb, A., ${ }^{3}$ Ibrahim, U. A., et ${ }^{* 4}$ Ahmed, S. G. \\ ${ }^{1}$ Département d'hématologie, Centre médical fédéral, Birnin Kudu, Nigéria \\ ${ }^{2}$ Département d'hématologie, hôpital d'enseignement Rasheed Shekoni, Dutse, Nigéria \\ ${ }^{3}$ Département de pédiatrie, Hôpital universitaire Aminu Kano, Kano, Nigéria
}


${ }^{4}$ Département d'hématologie, Hôpital universitaire Aminu Kano, Kano, Nigéria

*Correspondance à: drsagirahmed@yahoo.com; +2348034418015

\section{Abstrait:}

Contexte: Dans les populations d'endémie palustre, le trait drépanocytaire (SCT) protège à la fois contre le paludisme grave et non sévère, mais des incohérences existent quant à l'effet protecteur de la SCT sur la parasitémie asymptomatique du paludisme (AMP). De manière surprenante, l'effet des phénotypes Hb sur l'AMP n'a pas été exploré chez les donneurs de sang au Nigéria ou dans d'autres pays d'endémie palustre, où les risques de PMA et de paludisme transmis par transfusion (TTM) sont élevés. L'objectif de cette étude est de déterminer le risque d'AMP par rapport aux phénotypes $\mathrm{Hb}$ des donneurs (SCT versus HbAA), et d'élucider les implications cliniques de I'AMP en ce qui concerne le risque de TTM vis-à-vis de la pratique de la médecine transfusionnelle au Nigéria, et par implication d'autres pays tropicaux d'endémie palustre.

Méthodologie: Une analyse de 100 donneurs de sang avec AMP (cas) et 100 donneurs sans AMP (témoins) a été réalisée. Les fréquences de SCT et d'HbAA (déterminées par électrophorèse $\mathrm{Hb}$ ) parmi les cas et les témoins ont été comparées par test X2. Les risques d'AMP (détectés par microscopie) par rapport aux phénotypes Hb ont été exprimés en odds ratios (OR) par régression logistique cas-témoins.

Résultats: En comparaison avec les donneurs de sang sans AMP (témoins), les donneurs avec AMP avaient des fréquences plus faibles de SCT $(12 \%$ vs $28 \%, p<0,05)$ avec des fréquences plus élevées correspondantes d'HbAA $(88 \%$ vs $72 \%, p<0,05)$. L'HbAA est associée à un risque élevé d'AMP (OR=2,91, IC à 95\%: $2,10-3,48, p=0,021)$, tandis que la SCT est associée à un faible risque d'AMP (OR=0,49, ICà95\%: $0,27-0,73, p=0,032)$. Conclusion: Cette découverte montre que le donneur SCT est un atténuateur subreptice du risque d'AMP et de TTM dans les tropiques. Par conséquent, les patients qui sont sélectivement transfusés avec du sang HbAA (par exemple, les nouveau-nés et les patients atteints de drépanocytose) pourraient être plus à risque de TTM, et ces patients ont besoin d'une surveillance post-transfusionnelle plus étroite. Le risque de TTM appelle une hémovigilance post-transfusionnelle diligente au Nigéria et dans d'autres pays tropicaux endémiques du paludisme en Afrique

Mots clés: donneurs de sang, trait drépanocytaire, parasitémie asymptomatique du paludisme, paludisme transmis par transfusion

\section{Introduction:}

Haemoglobin $\mathrm{S}(\mathrm{HbS})$ is the best characterized human genetic polymorphism that is strongly associated with resistance to malaria (1). HbS is a structural variant of $\mathrm{HbA}$ that arose as a result of GAG > GTG base transition at codon- 6 of the $\beta$-globin gene on chromosome-11, which corresponds to the substitution of glutamic acid (polar, hydrophilic amino acid) by valine (neutral, hydrophobic amino acid) at position- 6 of the $\beta$-globin chain of the haemoglobin molecule (1). Consequently, HbS has less anionic potential, slower electrophoretic mobility and reduced deoxygenated solubility that leads to polymerization, and red cell sickling (2). The sickle cell trait (SCT) refers to the heterozygous inheritance of the sickle $\beta$-gene (3). The SCT protects against severe falciparum malaria and confers survival advantage in populations living in malaria endemic countries (4). This is attained through the process of natural selection (5), mediated by the phenomenon of balanced polymorphism (6), and executed by immunological and biochemical mechanisms that protect individuals with SCT from malaria (7). Consequently, the prevalence of SCT in Nigeria and other tropical African countries is up to $25-30 \%$ in the general population (4).

In Nigeria, the eligibility of prospective donors is determined by pre-donation assessment of health status. A significant part of the assessment takes the form of verbal and/or questionnaire screening with reliance on answers to simple standard questions relating to general health, medical and social history, and simple general physical examination including the measurements of weight and blood pressure $(8,9)$. Persons who are between the ages of 18 and 65 years, and have passed the pre-donation medical assessment with negative test results for HIV, hepatitis B and C viruses, and syphilis, with haemoglobin $(\mathrm{Hb})$ levels of more than $13.5 \mathrm{~g} / \mathrm{dl}$ for males or 12.5 $\mathrm{g} / \mathrm{dl}$ for females are acceptable as donors (9). Individuals with SCT are genetically heterozygous for the sickle $\beta$-globin gene and their red cells have the HbAS phenotype expressing both $\mathrm{HbS}(20-40 \%)$ and $\mathrm{HbA}(60-$ $80 \%)(1,10)$. The relative abundance of $\mathrm{HbA}$ prevents undue sickling and haemolysis under physiological conditions, hence the red cell life span is normal in SCT and affected individuals are symptomless, non-anaemic, and have normal life expectancy $(10,11)$. Therefore, SCT does not in any way reduce the chances of passing routine pre-donations tests in affected individuals. Consequently, persons with SCT constitute a significant proportion of eligible blood donors in tropical African countries such as Nigeria, where up to one quarter (21-27\%) 
of blood donors carry the SCT $(12,13)$. Unfortunately, the SCT blood has certain disadvantages; it is unsuitable for some blood banking procedures (e. g. leuco-filtration) and also inappropriate for transfusing certain vulnerable patients (e. g. foetuses, neonates and sickle cell disease patients) (9). Therefore, the World Health Organization (WHO) does not consider SCT as a contraindication for blood donation as long as the blood is not subjected to leuco-depletion or used for transfusing foetuses (intra-uterine), neonates and patients with sickle cell disease (SCD) (9).

Extensive systematic and meta-analytical review revealed that various studies had consistently shown that SCT definitively protects against both severe and uncomplicated malaria in the tropics, wherein SCT confers greater than $90 \%$ protection from severe malaria and up to $50 \%$ protection against symptommatic uncomplicated malaria (7). However, inconsistencies exist regarding whether or not the SCT protects against asymptomatic malarial parasitemia (AMP) in tropical populations. While some studies $(7,14)$ suggested that SCT was protective and associated with low prevalence of $A M P$, other studies $(7,15)$ found no such protective association between SCT and AMP in tropical populations. These inconsistencies call for further studies. Surprisingly, to the best of our knowledge, the effect of $\mathrm{Hb}$ phenotypes on the prevalence of AMP has not been explored among blood donors in Nigeria or other malaria-endemic countries, where transfusion safety is low and the risk of transfusion transmitted malaria (TTM) is high $(16,17)$. We therefore intended to study the effect of $\mathrm{Hb}$ phenotypes (SCT versus $\mathrm{HbAA}$ ) on the prevalence and risk of AMP among apparently healthy blood donors in Nigeria.

As in many other tropical countries, donor screening for AMP and post transfusion haemovigilance of patients are not routinely conducted in Nigeria, hence the exact incidence of TTM among transfused patients in Nigeria is unknown $(18,19)$. However, the incidence of TTM is presumably high because the prevalence of AMP among Nigerian donors was reported to range from $6 \%$ to as high as $45.8 \%(16,17)$. Nonetheless, we predicted that SCT would protect donors against AMP, while HbAA would increase donors' susceptibility to AMP. We thus hypothesized that SCT and HbAA would be associated with low and high risks of AMP among blood donors respectively. If our prediction and hypothesis are correct, AMP positive blood donors will have significantly lower relative frequencies of SCT and higher relative frequencies of $\mathrm{HbAA}$ phenotypes in comparison with randomly selected normal (AMP negative) control donors. In order to test our prediction and hypothesis, we conducted an analysis of the pattern and frequencies of haemoglobin phenotypes (SCT versus HbAA) among AMP positive blood donors in comparison with randomly selected normal (AMP negative) control donors.

The aim of this study was two-folds; first, to determine the risk of AMP with respect to $\mathrm{Hb}$ phenotypes (SCT versus $\mathrm{HbAA}$ ) of blood donors, and secondly, to elucidate and review the clinical implications of AMP positivity among blood donors with respect to the risk of TTM vis-à-vis the practice of transfusion medicine in Nigeria and, by implication, in other malaria endemic tropical African countries.

\section{Materials and method:}

\section{Study setting and design}

This is a 'case-control' study with a total of 200 apparently healthy blood donors; 100 with AMP (as case) and 100 without AMP (as control). The study was conducted to investigate the risk of AMP with respect to $\mathrm{Hb}$ phenotypes (SCT versus HbAA) and carried out during the year 2017 at Rasheed Shekoni Teaching Hospital, Dutse, North-West Nigeria, and Federal Medical Centre, Birnin Kudu, North-West Nigeria. The study was conducted after obtaining informed consent of the donors and approval of the ethical committees of the hospital.

\section{Subject participants, inclusion and exclusion criteria}

Apparently healthy donors who passed the pre-donation clinical evaluation and $\mathrm{Hb}$ estimation, and tested negative for infectivity markers of hepatitis B and C, HIV and syphilis were consecutively recruited at the time of blood donation in the blood bank of the study hospital. Prospective donors who failed any of the aforementioned pre-donation assessments were excluded from this study.

\section{Microscopic evaluation and speciation of AMP}

All recruited donors were investigated for AMP by manual technique based on microscopic examination of Giemsa-stained thick blood smears and Leishman-stained thin blood smears using standard techniques (22). If no parasite was found in 100 oil-immersion microscopic fields of a thick smear, the sample was considered negative for malaria parasite (22). Samples positive for malaria parasite by thick smear were further tested by thin smear for morphological identification of parasite species, 
while parasite density was microscopically estimated on the thick smear by counting the number of asexual forms of the parasites per high power field (HPF) (22). Parasites density levels were documented by using the plus $(+)$ grading system (22); count of 1-10 parasites per $100 \mathrm{HPF}=(1+), 11-100$ parasites per 100 $\mathrm{HPF}=(2+), 1-10$ in single HPF $=(3+)$, and $>10$ parasites in single HPF $=(4+)(22)$.

Donor categorization on the basis of microscopy results for AMP

Donors with AMP $(n=100)$ were categorized as 'case'. Equal number of subjects were randomly selected from donors without AMP $(n=100)$ to serve as 'control'.

\section{Determination of ABO blood groups}

The ABO blood groups were determined by standard manual techniques using monoclonal anti-A and anti-B against donors' red cells in saline tubes at room temperature, and read for agglutination after 15 min incubation. On the basis of the pattern of agglutination, donor red cells were categorized as group $O, A$, $B$ or $A B(23)$.

\section{Determination of $\mathbf{H b}$ phenotypes}

The $\mathrm{Hb}$ phenotypes were determined by $\mathrm{Hb}$ electrophoresis at $\mathrm{a} \mathrm{pH}$ of 8.6 on cellulose acetate paper. On the basis of electrophoretic patterns, the $\mathrm{Hb}$ phenotypes were categorized as normal (HbAA) or SCT (HbAS) (24).

\section{Statistical analysis}

Statistical analyses of data were performed using the Statistical Package for the Social Sciences (SPSS) software version 15.0 (SPSS Inc., Chicago, IL, USA). Frequency distribution of $\mathrm{ABO}$ blood groups and $\mathrm{Hb}$ phenotypes among study donors study cohort were presented as percentages. Age of study donors study cohort was calculated in years and presented as mean and standard deviation, while gender profile of the study donors study cohort was presented as proportions (percentages) of male and female donors. Mean values of data were compared between case donors (with AMP) and control donors (without AMP) by Student's $t$-test and proportions (percentages) by $X^{2}$-test. $P$ value less than 0.05 was considered statistically significant.

The risks of AMP associated with SCT and HbAA were calculated as Odds ratios (OR) and separately determined by age and gender adjusted case-control logistic regression analysis using the following inputs; OR for the risk of AMP associated with SCT = number of cases with SCT/number of cases with HbAA) / (number of controls with SCT/number of controls with $\mathrm{HbAA}$ ), and OR for the risk of AMP associated with $\mathrm{HbAA}=$ number of cases with $\mathrm{HbAA}$ /number of cases with SCT) / (number of controls with $\mathrm{HbAA} /$ number of controls with $\mathrm{SCT}$ ). A 'low risk OR' (i. e. OR<1) was considered to be statistically significant if the upper limit of $95 \%$ confidence interval ( $95 \% \mathrm{CI}$ ) was less than 1.0 with $p<0.05$; and a 'high risk OR' (i. e. $\mathrm{OR}>1$ ) was considered to be statistically significant if the lower limit of the $95 \%$ CI was greater than 1.0, with $p<0.05$. An OR was considered statistically insignificant if the range of its $95 \% \mathrm{CI}$ included 1.0 , with $p>0.05$.

\section{Results:}

All of the 100 donors with AMP had low parasite density level of $(1+)$, and the parasite morphology was consistent with $P$. falciparum in all cases. The distribution of donor age, gender and relative frequencies of $\mathrm{Hb}$ phenotypes and $\mathrm{ABO}$ blood groups among donors with AMP and control donors are shown in Table 1 . There were no significant differences between them with respect to mean age (28.5 years vs. 27.7 years, $p>0.05$ ), gender (male; $98 \%$ vs $97 \%, p>0.05$ and female; $2 \%$ vs $3 \%$, $p>0.05)$, relative frequencies of blood group-O ( $51 \%$ vs $53 \%, p>0.05)$, and non-O blood groups ( $49 \%$ vs $47 \%, p>0.05$ ).

However, the relative frequencies of $\mathrm{Hb}$ phenotypes revealed that donors with AMP had significantly lower frequencies of SCT (12\% vS $28 \%, p<0.05)$ and higher frequencies of $\mathrm{HbAA}$ ( $88 \%$ vs $72 \%, p<0.05)$ compared to control donors. The Odd Ratios for the risk of AMP with respect to donor $\mathrm{Hb}$ phenotypes are shown in Table 2, wherein HbAA is associated with a high OR of 2.91 (95\% CI: 2.10-3.48, $p=$ 0.021 ), while SCT is associated low OR of 0.49 (95\% CI: $0.27-0.73, p=0.032$ ). 
Table1: Age, gender, ABO groups, and Hb phenotypes among blood donors with AMP and control blood donors

\begin{tabular}{|c|c|c|c|}
\hline Parameters & $\begin{array}{l}\text { No of donors with AMP (\%) } \\
\qquad(n=100)\end{array}$ & $\begin{array}{l}\text { No of donors without } \\
\text { AMP (control donors) } \\
(\%)(n=100)\end{array}$ & $p$ value \\
\hline Mean age (years) $( \pm$ SD) & $28.5 \pm 3.2$ & $27.7 \pm 2.3$ & $>0.05$ \\
\hline Male & $98(98)$ & $97(97)$ & $>0.05$ \\
\hline Female & $2(2)$ & $3(3)$ & $>0.05$ \\
\hline Blood group-O & $51(51)$ & $53(53)$ & $>0.05$ \\
\hline Blood non-O groups $[A+B+A B]$ & 49 (49) & $47(47)$ & $>0.05$ \\
\hline $\mathrm{HbAA}$ & $88(88)$ & $72(72)$ & $<0.05$ \\
\hline SCT & $12(12)$ & $28(28)$ & $<0.05$ \\
\hline
\end{tabular}

Table 2: Odds ratios (OR) for the risk of AMP with respect to donor $\mathrm{Hb}$ phenotypes

\begin{tabular}{|c|c|c|c|c|c|}
\hline Hb phenotypes & $\begin{array}{c}\text { No of donors } \\
\text { with AMP } \\
(\%)(n=100)\end{array}$ & $\begin{array}{l}\text { No of donors } \\
\text { without AMP } \\
\text { (control } \\
\text { donors) }(\%) \\
(n=100)\end{array}$ & $\begin{array}{l}\text { OR values } \\
(95 \% \mathrm{CI})\end{array}$ & $P$ value & Inference \\
\hline $\mathrm{HbAA}$ & $88(88)$ & $72(72)$ & $2.91(2.10-3.48)$ & 0.021 & $\begin{array}{l}\text { HbAA is associated } \\
\text { with high risk of AMP } \\
\text { in blood donors }\end{array}$ \\
\hline SCT & $12(12)$ & $28(28)$ & $0.49(0.27-0.73)$ & 0.032 & $\begin{array}{l}\text { SCT is associated with } \\
\text { low risk of AMP in } \\
\text { blood donors }\end{array}$ \\
\hline
\end{tabular}

\section{Discussion:}

With the largest back population of over 200 million, SCT frequency of $25-30 \%$ and SCD prevalence of $1-3 \%$, Nigeria carries the heaviest burden of the sickle cell gene in the world (20). Moreover, malaria is endemic in Nigeria, which has a year-round transmission with up to $97 \%$ of the population being at risk of malaria infection (21). Thus, virtually the entire Nigerian population is at risk of malaria infection, which is predominantly caused by $P$ falciparum specie (21). Inspite of the fact that the prevalence rates of SCT and AMP are high in Nigeria $(12,13,16,17)$, and despite the WHO recommendation that countries with high prevalence of SCT and malaria infection should screen their donors (9), Nigerian blood banks do not routinely screen prospective donors for SCT or AMP. Therefore, both SCT and AMP are prevalent among apparently healthy blood donors in Nigeria.

Nigerian blood donor panels are predominated by young people as revealed by the donor mean ages of less than 30years reported in this study. This is consistent with the demographic profiles of Nigerian blood donors as reported in previous studies (25). This pattern is a manifestation of the demographic structure of Nigeria, which is a developing country with a relatively young population in comparison to the developed countries (26). In addition, younger people are relatively more educated (26), and are therefore more amenable to donor recruitment campaigns. The overwhelmming preponderance of male donors as seen in this study is a reflection of the general low level of blood donation among the female population in Nigeria (27). Despite the fact that blood donation is acceptable from healthy females that are not pregnant or breast feeding (9), there is a misconception in the general Nigerian population that women are not eligible to donate blood (27). There is therefore the need to rectify this misconception by re-configuring our donor mobilization strategy in order to target and sensitize the female sector (28), which constitutes about half of the Nigerian population (26). Lack of significant differences in donor age, gender and $\mathrm{ABO}$ blood group distributions between donors with AMP and control donors suggested that these parameters did not affect the risk of AMP among the blood donors studied in this study, which is consistent with the findings of previous studies (17). However, we found striking and significant differences between donors with AMP and control donors with respect to the distribution of $\mathrm{Hb}$ phenotypes among the study population.

The distribution of $\mathrm{Hb}$ phenotypes among our control donors (without AMP) revealed that $\mathrm{HbAA}$ and $\mathrm{SCT}$ occurred with 
relative frequencies of $72 \%$ and $28 \%$ respectively, which is consistent with the relative frequencies of $\mathrm{Hb}$ phenotypes in the general population in Nigeria (20). In contrast, donors with AMP showed a distorted distribution of $\mathrm{Hb}$ phenotypes with significantly higher relative frequency of $\mathrm{HbAA}(88 \%)$ and lower relative frequency of SCT $(12 \%)$. Logistic regression analysis of the differences in the relative frequencies of $\mathrm{Hb}$ phenotypes vis-à-vis the risk of AMP among blood donors revealed OR of 2.91 and 0.45 for HbAA and SCT respectively. These ORs suggested that donors with HbAA were about 3 times more likely to have AMP than control donors, while donors with SCT were about $50 \%$ less likely to have AMP than control donors. Therefore, the two ORs implied that $\mathrm{HbAA}$ was associated with high risk of AMP, while SCT was associated (and protective) with low risk of AMP among blood donors.

Our findings are at variance with previous studies, which reported that SCT did not protect against AMP $(7,15)$. However, our findings are consistent with our working hypothesis, and are in conformity with previous studies, which reported that SCT protected against $\operatorname{AMP}(7,14)$. Moreover, these findings are in keeping with the fact that persons with SCT resist malaria infection through innate, immunological and biochemical mechanisms, which include reduced red cell invasion by the parasite, low intra-red cell parasite proliferation, parasite-induced red cell sickling and phagocytosis, reduced rosetting and cytoadherence of parasitized red cells, and enhanced cellular and humoral immune response against the malaria parasite (7).

The result of our study has triple clinical implications with respect to the risk of TTM in the practice of transfusion medicine in the tropics. First, the results suggest that blood donated by persons with $\mathrm{HbAA}$ is associated high risk of TTM. Second, blood donated by persons with SCT is associated with low risk of TTM, hence we believe that donor SCT is an important but surreptitious mitigator of the risk of TTM in the tropics. Third, patients who are selectively transfused with HbAA blood would be at increased risk of acquiring TTM. Suffices to say that TTM is a serious but inadequately quantified (i. e. exact incidence is unknown due to lack of post transfusion haemovigilance) complication of blood transfusion in Nigeria and other malaria endemic countries $(18,19)$. Nonetheless, the risk of acquiring TTM would certainly be higher among patients with various forms of vulnerabilities and immune incompetence as may be encountered in the elderly, pregnant women, neonates and children, and patients with cancers, HIV/AIDS and SCD (29). However, two categories of patients (neonates and SCD patients) deserve careful consideration because in addition to their individual vulnerabilities, they are selectively transfused with HbAA blood, which we found (in this study) to be associated with high risk of AMP and by implication, high risk of TTM.

Nigeria has one of the highest birth rates in the world (26), with a commensurate high frequency of neonatal anaemia, jaundice and transfusion due to high prevalence of sepsis, prematurity, and G6PD-deficiency (30). The standard of care for best practice for neonatal transfusion requires selective use of HbAA blood $(9,31)$, which unfortunately is associated with high risks of AMP and TTM as seen in this study. It is well known that neonates are naturally protected from malaria by two barriers viz maternal antibodies and HbF $(32,33)$. Nevertheless, these neonatal protective barriers can be easily overcome by direct transfusion of malaria infected blood for four reasons. First, neonates are selectively transfused with $\mathrm{HbAA}$, which carries higher risk of AMP as found in this study. Second, neonates are often transfused with fresh blood (31), and malaria parasites remain viable in stored refrigerated blood for only about two weeks (34), hence fresh blood is more likely to transmit malaria than old stored blood (19). Third, relative to the size of the neonate, the parasite dose in infected donor blood is often massive, and it has been suggested that a massive infective dose would easily overwhelm the protective barriers and lead to the establishment of malaria (35). Fourth, neonatal transfusions are often given by exchange blood transfusion (EBT) procedures (30), and EBT invariably removes the protective maternal antibodies (32) and HbF (33) in the discarded neonatal blood. For the reasons above, TTM is an important complication of neonatal transfusion in Nigeria and other malaria endemic countries (36). Therefore, neonates that are transfused must be closely monitored for any clinical manifestations of TTM.

Nigeria carries the heaviest burden of SCD in the world (20). The management of SCD is transfusion intensive (37), and in similarity with neonatal transfusion, the standard of care for best practice for SCD transfusion requires selective use of $\mathrm{HbAA}$ blood $(9,38)$. Although SCD patients are fundamentally vulnerable to malaria by virtue of their immune compromised status (39), we believe that the selective transfusion of HbAA blood would increase their risks of acquiring TTM. 
Consequently, TTM is an important complication seen among SCD patients who had received blood transfusion from donors within or originating from malaria endemic countries $(40,41)$. Therefore, SCD patients and their parents should be adequately counseled to strictly comply with their routine anti-malarial chemo-prophylaxis as is usually incorporated in the standard of care for SCD patients who are resident in their native malaria-endemic tropical countries (42). Nonetheless, SCD patients who are transfused must be closely monitored for any clinical manifestations of TTM.

One limitation in our study was the use of the plus $(+)$ grading system to estimate malaria parasitaemia as opposed to the more accurate but time-intensive parasitemia estimation per microlitre of blood, which is usually done in research laboratories. However, the plus (+) grading system is the commonest method for parasitemia estimation and recommended by the WHO (22) for high turnover routine clinical laboratories such the one from which our study was conducted.

\section{Conclusion:}

This study showed that $\mathrm{HbAA}$ is associated with high risk of AMP among blood donors, while SCT was protective and associated with low risk of AMP. These findings imply that blood donated by persons with HbAA is associated high risk of TTM, while blood donated by persons with SCT was protective and associated with low risk of TTM. There is the need to validate the findings of this study by conducting larger studies. Meanwhile, the result of this study suggests that donor SCT is an important but surreptitious mitigator of the risk of AMP and TTM in the tropics. Therefore, patients who are selectively transfused with HbAA blood (e. g. neonates and SCD patients) would be at greater risks of acquiring TTM, and such patients need closer post transfusion monitoring. The risk of acquiring TTM by neonates and patients with SCD, and indeed all other transfusion dependent patients calls for greater post transfusion haemovigilance, which unfortunately is lacking in Nigeria and most other tropical countries.

\section{Conflict of interest:}

Authors declare no conflict of interest.

\section{References:}

1. Flint, J., Harding, R. M., Boyce, A. J., et al. The population genetics of the hemoglobinopathies. Bailliere's Clin Haematol. 1993; 6: 215-22.
doi:10.1016/S0950-3536(05)80071-X.

2. Kaul, D. K., Fabry, M. E., and Nagel, R. I. The pathophysiology of vascular obstruction in the sickle cell syndromes. Blood Rev. 1996; 10: 2944. doi:10.1016/S0268-960X(96)90018-1.

3. Pecker, L. H., and Naik, R. P. The current state of sickle cell trait: implications for reproductive and genetic counseling. Blood. 2018; 132: 2331-2338. doi:10.1182/blood-2018-06-848705.

4. Fleming, A. F., Storey, J., Molineaux, L., et al. Abnormal haemoglobins in the Sudan savanna of Nigeria: I. Prevalence of haemoglobins and relationships between sickle cell trait, malaria and survival. Ann Trop Med Parasitol. 1979; 73: 16172. doi:10.1080/00034983.1979.11687243.

5. Elguero, E., Délicat-Loembet, L. M., Rougeron, V., et al. Malaria continues to select for sickle cell trait in Central Africa. Proc Natl Acad Sci USA. 2015; 112: 7051-7054. DOI:10.1073/pnas.1505665112.

6. Olatunji, P. O. Malaria and the sickle gene: polymorphism balance in favour of eradication. Ann Health Res. 2018; 4: 88- 96.

doi:10.30442/ahr.0402-1-12.

7. Gong, L., Parikh, S., Rosenthal, P. J., and Greenhouse, B. Biochemical and immunological mechanisms by which sickle cell trait protects against malaria. Malar J. 2013; 12: 317.

doi:10.1186/1475-2875-12-317

8. Kakaiya, R., Aronson, C. A., and Julleis, J. Whole blood collection and component processing at blood collection centers. In: Roback, J. D. (ed). Technical Manual. 17th ed. Bethesda: AABB; 2011: 187-226.

9. World Health Organization. Blood donor selection: guidelines on assessing donor suitability for blood donation. Geneva, 2012.

https://apps.who.int/iris/bitstream/handle/10665/ 76724/9789241548519_eng.pdf. [Accessed Oct 1, 2020].

10. Ahmed, S. G., and Ibrahim, U. A. Haemoglobin-S in sickle cell trait with papillary necrosis. $\mathrm{Br}$ ] Haematol. 2006; 135: 415-416. doi:10.1111/j.1365-2141.2006.06318.x

11. Barbedo, M. M. R., and McCurdy, P. R. Red cell life span in sickle cell trait. Acta Haematol. 1974; 15: 339-342. doi:10.1159/000208316.

12. Ahmed, S. G., Hassan, A. W., and Ibrahim, U. A. The frequency and clinical significance of structural haemoglobin variants in donor blood at university of Maiduguri teaching hospital. Niger J Surg Res. 2000; 2: 127-130. doi:10.4314/njsr.v2i3.12199.

13. Garba, N., Danladi, S. B., Abubakar, H. B., et al. Distribution of haemoglobin variants, $A B O$ and $R h$ blood groups in blood donors attending Aminu Kano Teaching Hospital, Nigeria. Clin Med J. 2016, 2:20-24. http://www.aiscience.org/journal/cmj.

14. Danquah, I., Ziniel, P., Eggelte. T. A., et al. Influence of haemoglobins $\mathrm{S}$ and $\mathrm{C}$ on predominantly asymptomatic Plasmodium infections in northern Ghana. Trans R Soc Trop Med Hyg. 2010; 104: 713-719. doi: 10.1016/j.trstmh.2010.08.001.

15. Migot-Nabias, F., Pelleau, S., Watier, L., et al. Red blood cell polymorphisms in relation to Plasmodium falciparum asymptomatic parasite densities and morbidity in Senegal. Microb Infect. 2006; 8: 2352-2358.

doi:10.1016/j.micinf.2006.03.021.

16. Ahmed, S. G., Ibrahim, U. A., and Ibrahim, G. Prevalence and clinical significance of malaria parasitemia in donor blood in Maiduguri, Nigeria. Niger J Parasitol. 2001; 22: 29-34.

doi: 10.4314/njpar.v22i1.37755.

17. Ezeonu, C. M., Adabara, N. U., Garba, S. A., et al. The risk of transfusion transmitted malaria and the need for malaria screening of blood donors in 
Abuja, Nigeria. Afr J Clin Exper Microbiol. 2019; 20: 195-201. doi:10.4314/ajcem.v20i3.4.

18. Aneke, J. C., Ezeama, N., Okocha, C. E., et al. Knowledge, attitude and practice of haemovigilance among healthcare professionals in a Nigerian Tertiary Hospital. Egypt J Haematol. 2017; 42: 108-116. doi:10.4103/ejh.ejh_25_17.

19. Faruk, J. A. Blood transfusion malaria: A literature review. Ann Niger Med. 2016; 10: 49-57. doi:10.4103/0331-3131.206210.

20. Galadanci, N., Wudil, B. J., Balogun, T. M., et al. Current sickle cell disease management practices in Nigeria. Int HIth. 2014; 6: 23-28 doi:10.1093/inthealth/int022.

21. United States Embassy in Nigeria. Nigeria malaria factsheet.

http://www.photos.state.gov/libraries/nigeria/./De cember-MalariaFactSheet2011.pdf. [Accessed Oct $1,2020]$.

22. World Health Organization. Basic malaria microscopy 2010; 2nd ed.

https://apps.who.int/iris/handle/10665/44208. [Accessed Oct 1, 2020].

23. Rowley, M., Cantwell, C., and Milkins, C. Laboratory aspects of blood transfusion. In: Bain, B., Bates, I., and Laffan, M. (eds). Practical Haematology. $12^{\text {th }}$ ed. Elsevier, London 2017: 470-496.

24. Wild, B., and Bain, B. Investigation of abnormal haemoglobins and thalassaemia. In: Bain, B., Bate, I., and Laffan, M. (eds). Practical Haematology. $12^{\text {th }}$ ed. Elsevier, London 2017: 282-311.

25. Ugwu, A. O., Madu, A. J., Efobi, C. C, et al. Pattern of blood donation and characteristics of blood donors in Enugu, Southeast Nigeria. Niger J Clin Pract. 2018; 21: 1438-1443.

26. National Population Commission. Nigeria Demographic and Health Survey 2018. Abuja, Nigeria. https://www.dhsprogram.com. [Accessed: Oct 1, 2020].

27. Erhabor, O., Isaac, Z., Abdulrahaman, Y., et al. Female gender participation in the blood donation process in resource poor settings: case study of Sokoto in north western Nigeria. J Blood Disord Transfus. 2013; 5: 176. doi:10.4172/2155-98641000176.

28. Anyanwu-Yeiya, C. C., Sonubi, O., and Kotila, T. R. Targeting females as voluntary non remunerated donors in developing nations. J Blood Disord Transfus. 2015; S4: S4-002. doi:10.4172/21559864.1000S4-002.

29. Deroost, K., Pham, T. T., Opdenakker, G., et al. The immunological balance between host and parasite in malaria. FEMS Microbiol Rev. 2016; 40: 208-257. DOI:10.1093/femsre/fuv046.

30. Olusanya, B. O., Osibanjo, F. B., Mabogunje, C. A., et al. The burden and management of neonatal jaundice in Nigeria: a scoping review of the literature. Niger J Clin Prac. 2016; 19: 1 - 7. doi: 10.4103/1119-3077.173703.

31. Ahmed, S. G., and Ibrahim, U. A. Donor blood selection criteria for neonatal red cell transfusion: general and tropical perspectives. Trop J HIth Sci. 2018; 25: 1-10.

32. Reynaldi, A., Dent, A. E., Schlub, T. E., et al. Interaction between maternally derived antibodies and heterogeneity in exposure combined to determine time-to-first Plasmodium falciparum infection in Kenyan Infants. Malar J. 2019; 18: 19. DOI:10.1186/s12936-019-2657-6.

33. Billig, E. M. W., McQueen, P. G., and McKenzie, F. E. Foetal haemoglobin and the dynamics of paediatric malaria. Malar J. 2012; 11: 396. doi:10.1186/1475-2875-11-396.

34. Chattopadhyay, R., Majam, V. F., and Kumar, S. Survival of Plasmodium falciparum in human blood during refrigeration. Transfusion. 2011; 51: 630635

35. Sodeinde, O., and Dawodu, A. H. Neonatal transfusion malaria: A growing clinical problem. Niger. J Paediatr. 1985; 12: 57-60.

36. Iheonu, F. O., Fajolu, I. B., and Ezeaka, C. V. Transfusional malaria in the neonatal period in Lagos, South-West Nigeria. PLoS One. 2018; 13: e0195319. doi:10.1371/journal. pone.0195319.

37. Adewoyin, A. S., and Obieche, J. C. Hypertransfusion therapy in sickle cell disease in Nigeria. Adv Hematol. 2014; Article ID: 923593. doi:10.1155/2014/923593.

38. Diaku-Akinwumi, I. N., Abubakar, S. B., Adegoke, S. A., et al. Blood transfusion services for patients with sickle cell disease in Nigeria. Int HIth. 2016; 8: 330-335. doi:10.1093/inthealth/ihw014.

39. Ahmed, S. G. The role of infection in the pathogenesis of vaso-occlusive crisis in patients with sickle cell disease. Mediterr J Hematol Infect Dis. 2011; 3: e2011028.

40. Maier, C. L., Gross, P. J., Dean, C. L., et al. Transfusion-transmitted malaria masquerading as sickle cell crisis with multisystem organ failure. Transfusion. 2018; 58; 1550-1554 doi: $10.1111 /$ trf. 14566 .

41. Guindo, A., Toure, B. A., Guindo, P., et al. Transmission of Plasmodium falciparum by red blood cell transfusions in the management of sickle cell disease patients in Mali. Transfus Med. 2016; 26: 153-155. doi:10.1111/tme.12294.

42. Frimpong, A., Thiam, L. G., Arko-Boham, B., et al. Safety and effectiveness of antimalarial therapy in sickle cell disease: a systematic review and network meta-analysis. BMC Infect Dis. 2018; 18: 650. doi:10.1186/s12879-018-3556-0. 